\title{
A psicologia do trabalho e os processos de formação de educadores na educação profissional de nível básico: itinerários diversos, encruzilhadas constantes
}

(Work psychology and the processes of educators' qualification in senior high-school professional education: diverse itineraries, constant crossroads)

(La psicología del trabajo y los procesos de formación de educadores de la educación profesional de nivel básico: itinerarios diversos, encrucijadas constantes)

\section{João César de Freitas Fonseca*}

\begin{abstract}
Resumo
Este trabalho pretende aprofundar os conhecimentos sobre a atividade dos educadores da educação profissional (EP) de curta duração. Recorre à metodologia da Psicologia do trabalho de Yves Clot, conhecida como clínica da atividade, que tem inspiração vygotskiana, e usa técnicas qualitativas de investigação (registro em vídeo, autoconfrontação direta e cruzada). Foram observados cinco programas de educação profissional dos setores público e privado em Belo Horizonte. Os resultados indicaram a prevalência de aspectos subjetivos na construção do gênero profissional formado pelos educadores de EP, confirmando Clot (2006): o gênero é fortemente influenciado pelo estilo profissional. A análise dos dados obtidos também sugere a convergência entre Psicologia do trabalho e Pedagogia crítica, recomendando o aprofundamento das investigações qualitativas sobre as iniciativas de EP de nível básico. Finalmente este trabalho recomenda que as políticas públicas no campo da EP de nível inicial ofereçam maior atenção às contribuições dos trabalhadores que as executam.
\end{abstract}

Palavras-chave: Psicologia do trabalho; clínica da atividade; educação profissional.

\section{Abstract}

This work intends to deepen the knowledge on the activity of short-term Educators of Professional Education (PE). It is based on the methodology of Yves Clot's Work Psychology, known as activity clinic, of Vygotskian

Texto recebido em agosto/2008 e aprovado para publicação em dezembro/2008.

* Doutor em Educação pela Faculdade de Educação da UFMG, professor adjunto e coordenador do Laboratório de Psicologia Organizacional e do Trabalho (LaPOT) da Pontifícia Universidade Católica de Minas Gerais, PUC Minas, e-mail: joaocesar.fonseca@yahoo.com.br 
inspiration, and uses qualitative inquiry techniques (video record, direct and cross self-confrontation). Five programs of Professional Education of the public and private sectors in Belo Horizonte were observed. Results indicated the prevalence of subjective aspects in the construction of the professional sort formed by PE educators, confirming Clot (2006): the sort is strongly influenced by professional style. The analysis of the data also suggests the convergence between work psychology and critical pedagogy, recommending deeper qualitative inquiries on the initiatives of senior high-school PE. Finally, it is also recommended that public policies in the field of initial level PE pay greater attention to the contributions of those in charge of them.

Key-words: Work psychology; activity clinic; professional education.

\section{Resumen}

Este trabajo se prepone profundizar el conocimiento en la actividad de los educadores de la Educación Profesional (EP) de duración corta. Apela a la metodología de la psicología del trabajo de Yves Clot, conocida como clínica de la actividad, que tiene inspiración vygotskiana y usa las técnicas cualitativas de investigación (registro en vídeo, la autoconfrontación directa y cruzada). Cinco programas de educación profesional en Belo Horizonte fueron observados, de los sectores público y privado. Los resultados indicaron el predominio de aspectos subjetivos en la construcción de la clase profesional formada por los educadores de EP, lo que confirma Clot (2006): la clase está influenciada por el estilo profesional. El análisis de los datos conseguidos también sugiere la convergencia entre la psicología del trabajo y la pedagogía crítica, por lo que se recomienda la profundización de las investigaciones cualitativas en las iniciativas de EP del nivel básico. Finalmente, este trabajo recomienda que las políticas públicas en el campo de EP del nivel inicial ofrezcan una atención mayor a las contribuciones de los trabajadores que las ejecutan.

Palabras clave: Psicología del trabajo. Clínica de la actividad. Educación Profesional.

\section{Introdução}

Formadores, professores, instrutores... Identidade(s) e gênero profissional

formação de educadores e professores é tema constante nas produções
do campo da Educação, perpassando pelos diferentes níveis de ensino
(Bicudo \& Junior, 1996; Perrenoud, 2002; Tardif, 2002; Nóvoa, 1992,
1995). De forma geral, o que se observa, porém, é uma menor atenção 
dos pesquisadores pela educação profissional, diferentemente de outros níveis de ensino. Um exemplo interessante pôde ser encontrado na 29a Reunião Anual da Associação Nacional de Pós-Graduação em Educação (ANPED), quando o Grupo de Trabalho no 8 (Formação de professores) contou com a apresentação de 29 trabalhos. Desses, apenas um era dirigido à formação de educadores para a educação profissional (Burnier, 2007b). Impõe-se, portanto, para o nosso trabalho, a alternativa de buscar estabelecer paralelos entre os estudos sobre a formação de educadores em geral e a formação de educadores de EP.

Do ponto de vista histórico, encontramos uma argumentação bastante consistente em Nosella (2004), o qual, dispondo-se a fazer um esboço histórico da formação dos educadores e dos professores, chega a sugerir critérios para diferenciação dessas categorias, afirmando que:

O educador é educado pelo Estado, no sentido gramsciano do termo, isto é, pela sociedade política e pela sociedade civil, das quais ele próprio direta e indiretamente participa. [...] Ele é, ainda, educado pela e na convivência familiar, pelas tradições culturais e pela linguagem, pelos hábitos e valores, pelas inúmeras e variadas instituições e organizações que compõem a sociedade civil, pelos amigos e vizinhos, pelas igrejas, pelas escolas, sindicatos, partidos, meios de comunicação social, etc. O professor, ao contrário, é preparado num específico nicho da sociedade, isto é, do Estado. Num espaço ou instituição próprios, organizados para produzirem o ensino-aprendizagem de alguma competência (grifos no original) (Nosella, 2004, p. 6).

Essa distinção entre o educador e o professor se fará bastante útil, quando a formação dos sujeitos que atuam como educadores de EP é feita pela sociedade civil, bem de conformidade com os termos acima delineados por Nosella, que, inspirado em Paulo Freire e Antonio Gramsci, conclui: "Professor e educador não se separam: o primeiro informa, o segundo dá o sentido humano e ético da própria informação" (Nosella, 2004, p. 27).

Além da dimensão ética e humana, há que se considerar aspectos políticos, técnicos e operacionais dessas atividades. Educador e professor são gêneros profissionais diferenciados, mas com zonas de interseção e sombreamento regidos por diferentes regimes de contratação e submetidos a diferentes processos de reconhecimento, remuneração, gestão e, evidentemente, formação. Nesse sentido, tem sido possível perceber, por 
parte do poder público e de pesquisadores, uma aproximação crescente, e bastante benéfica, entre a educação profissional e a educação de jovens e adultos (EJA), área cujas análises sobre modelos de formação de educadores podem ser aproveitadas, com certa cautela, para o campo da EP'.

De forma análoga à EP, também os educadores da EJA também têm sido historicamente chamados a lidar com os segmentos mantidos à margem da sociedade, colocando para ambas as modalidades de ensino o enfrentamento da lógica assistencialista e das práticas limitadoras do processo educacional. Em sua análise da formação dos educadores de EJA, Vera Ribeiro (1999) afirma:

[...] A perspectiva assistencialista e infantilizadora da educação de jovens e adultos é um fator que prejudica a constituição do campo, limitando as condições de se ofertar aos educadores uma formação adequada, que considere as especificidades do público dessa modalidade educativa (Ribeiro, 1999, p. 188-189).

Na mesma direção, caminham as anotações de Arroyo (2006, p. 17), para quem a formação do educador de EJA "sempre foi um pouco pelas bordas, nas próprias fronteiras onde estava acontecendo". Aceitando essa perspectiva de convergência entre EP e EJA, podemos tomar alguns apontamentos feitos por Di Pierro (2006)3 como parâmetros para a análise da formação de educadores de EP no Brasil atualmente, que poderiam ser resumidas nas seguintes considerações:

a) no caso da EP, semelhante à EJA, a formação acadêmica dos educadores nem sempre antecede a prática docente e também não pode se dizer que obrigatoriamente se lhe seja subsequente;

b) as experiências em curso podem e devem ser incorporados à constituição de diretrizes e políticas públicas de formação desses educadores, ao contrário do que se observa atualmente;

c) a formação dos educadores deve prepará-los para atuar tanto na rede pública quanto nos demais espaços educativos, como os movimentos e instituições sociais, priorizando o setor público;

\footnotetext{
Sob vários aspectos, a educação profissional relacionada à formação inicial e continuada (cursos de curta duração), que é nosso objeto de estudo, guarda muito mais aproximação com a EJA do que com os demais níveis da própria EP (níveis técnico e tecnológico), inclusive no que diz respeito aos estudos sobre a formação dos educadores. Como exemplo, podemos mencionar os estudos da Profa. Suzana Burnier, que focaliza os professores do Cefet-MG a partir de suas histórias de vida (Burnier, 2007a).

2 As considerações da autora citada referem-se, na verdade, ao seu trabalho como coordenadora da Equipe de Relatoria do I Seminário Nacional de Formação de Educadores de Jovens e Adultos, configurando-se assim como uma produção coletiva e não individual.
} 
d) com destaque para as contribuições freirianas, há possibilidades de articulação entre diferentes referências teóricas para sustentar a construção epistemológica em curso no campo da formação de educadores, tanto da EP quanto da EJA;

e) é extremamente importante a abertura de canais de diálogo entre os espaço de formação e os gestores dos programas dessas modalidades de ensino;

f) a formação dos educadores, tanto de EP quanto de EJA, deve considerar "sua dimensão socioeconômica e também sua subjetividade, sua corporeidade e a pluralidade de suas identidades singulares" (Di Pierro, 2006, p. 283).

Particularmente em relação a este último item, entendemos que a aproximação entre os processos de formação dos educadores de EP e de EJA nos reapresenta a demanda, de ambas as áreas, pelo desenvolvimento de novas pesquisas sobre as atividades desses sujeitos, incorporando olhares e compreensões de outros atores e campos. Incumbidos da responsabilidade de transmissão de saberes, tais educadores são muitas vezes chamados de professores por aqueles com quem se relacionam, embora nem sempre se reconheçam nessa condição, mostrando que a noção de identidade e de construção de um gênero profissional não se reduz às dimensões jurídicas ou contratuais. Trata-se de uma relação dialética, que afeta profundamente o modo de ser e de fazer desse trabalhador, que se forma e se deforma ao mesmo tempo na sua atividade.

A sobreposição de gêneros profissionais no processo de formação dos educadores de EP é reconhecida inclusive pelo poder público. Berger Filho (2002), na época em que atuava como secretário de Educação Média e Tecnológica do Ministério da Educação, afirmava que

O formador da educação profissional precisa ser, em primeiro lugar, um profissional da área, com dupla dimensão de conhecimento, de conteúdo e de experiência de trabalho dessa área. Além disso, ele vai ver o que e como se deve ensinar. Então, eu acho que é esse o tipo de distinção entre um professor profissional, que ó caso do professor de educação básica, inclusive de jovens e adultos, e um profissional professor. $\mathrm{O}$ professor da educação básica em qualquer modalidade é um professor profissional. O professor de educação profissional é antes de tudo um profissional professor. Ele é um profissional que será docente, que será formador, mas que pressupõe, sempre, o seu papel de profissional da área (Berger Filho, 2002, p. 75-76). 
É importante explicitar as diferenças entre os diferentes níveis de EP: no caso da EP de nível técnico, estamos nos referindo a professores que se ressentem de políticas mais consistentes para sua formação e cuja luta histórica pela profissionalização não pode ser desconsiderada. No caso da EP de nível básico ou inicial, estamos realmente nos referindo a profissionais de outras áreas que, em algum momento, começam a lecionar. Apesar de constituírem gêneros profissionais distintos, ambas as categorias acolhem sujeitos que desenvolvem práticas educativas vinculadas à transmissão de saberes técnicos e deparam perspectivas de formação extremamente fragmentadas, pontuais, carentes de marco regulatório e, muitas vezes, "coerentes com políticas de tendência privatizante” (Oliveira et alii, 2005, p. 25).

A essa altura, fica clara a profunda e complexa relação existente entre os processos de formação de educadores e a questão da profissionalização do professor. Ao enumerar os elementos para uma epistemologia da prática profissional dos professores e suas consequências para os processos formativos, Tardif (2002) analisa o que ele mesmo chama de "crise do profissionalismo" e propõe como metodologia que os pesquisadores interessados "em estudar os saberes profissionais da área de ensino" dirijam-se diretamente aos lugares onde os profissionais de ensino trabalham, numa perspectiva muito próxima à que adotamos neste trabalho, sob inspiração da análise psicológica do trabalho. Nos termos do próprio autor, "Chamamos de epistemologia da prática profissional o estado do conjunto dos saberes utilizados realmente pelos profissionais em seu espaço de trabalho cotidiano para desempenhar todas as suas tarefas" (grifos no original) (Tardif, 2002, p. 255).

Saviani (1996) apresenta argumentos sobre a formação do educador a partir do conceito de trabalho educativo, definido como o ato de produzir, direta e intencionalmente, em cada ser indivíduo singular, a humanidade que é produzida histórica e coletivamente pelo conjunto dos homens. Para ele, não são os saberes que determinam a formação do educador, mas a Educação que determina os saberes que entram na formação do educador.

Aranha (s/d), analisando os processos de formação docente para a educação profissional, apresenta conclusões bem convergentes. Para a autora, uma política de formação docente para a educação profissional deveria observar alguns aspectos ou princípios fundamentais, tais como:

- flexibilização, de forma a reduzir a ênfase tecnicista e valorizar a compreensão mais ampla do processo de formação, tanto do docente quanto do aluno;

- integração dasáreas deformação, em trêsblocos principais (conhecimentos 
gerais, conhecimentos partilhados e conhecimentos específicos);

- não dogmatização do conhecimento, vinculada ao estabelecimento de novas relações entre sujeitos envolvidos no processo de formação;

- imperativo de formação contínua, com ênfase para o diálogo e o intercâmbio dos diferentes saberes (formais, informais, experenciados ou não);

- aproximação entre teoria e prática, de forma a sinalizar para os futuros docentes os aspectos reais do exercício da profissão.

Tais pressupostos nos fazem pensar na possibilidade de que estejamos lidando com o que Charlot (2005) chama de "universais" da situação de ensino. Em outras palavras: ainda que diferentes, contendo modificações relacionadas aos métodos e público-alvo, seria razoável pensar que os itinerários formativos dos educadores de EP deveriam observar alguns princípios básicos, comuns à condição de educadores, independente do seu campo de atuação?

Charlot (2005), ao incorporar a ideia de relação do sujeito humano com o saber, lembra que ensinar e formar são termos antigos e mutuamente relacionados: "ensina-se um saber, forma-se um indivíduo" (Charlot, 2005, p. 90). Para ele:

Formar é preparar para o exercício de práticas direcionadas e contextualizadas, nas quais o saber só adquire sentido com referência ao objeto perseguido. Mas formar é também transmitir saberes que, se são transmitidos como simples instrumentos de uma prática, correm o risco não somente de se descaracterizarem, mas também de dificultarem a adaptação da prática ao contexto, e, se eles são transmitidos no seu estatuto de saberes constituídos em discurso coerente, correm o risco de "deslizar" sobre as práticas e de não ter valor instrumental (Charlot, 2005, p. 94).

Segundo Charlot, o processo de formação de educadores e de professores seria então regido por formas de mediação que poderiam ser compreendidas como a prática do saber (articulação entre a lógica das práticas e a dos discursos eruditos) e o saber da prática (conhecimento sobre a prática produzido pela pesquisa). Tais ideias permitem pensar na aplicabilidade de tais noções de formação de educadores, propostas originalmente para os níveis de ensino formal, em relação ao campo da EP, particularmente no que diz respeito aos cursos de curta duração. Isso porque a construção do educador de EP, na condição que estamos denominando como gênero profissional, passa por uma formação muito mais ampla do que a simples aquisição e manejo de técnicas. $\mathrm{Ou}$, apoiando-nos no próprio Charlot: 
O que está, então, em jogo na formação não é somente uma relação de eficácia a uma tarefa, é uma identidade profissional que pode tornar-se o centro de gravidade da pessoa e estruturar sua relação com o mundo, engendrar certas maneiras de "ler" as coisas, as pessoas e os acontecimentos (grifo nosso) (Charlot, 2005, p. 95).

Uma das referências mais importantes para a compreensão do tema formação de educadores é a obra do professor português Antônio Nóvoa (1995, 1992), da Universidade de Lisboa, que defende o uso da história de vida como recurso para a compreensão do processo de construção da identidade dos professores, evidenciando sua preocupação com a inclusão da categoria subjetividade nesse estudo.

Essas considerações surgem perfeitamente compatíveis com os pressupostos da Psicologia do trabalho que adotamos neste trabalho, convocando ao diálogo os conceitos de gênero profissional e de estilo profissional, cunhados por Yves Clot. Embora esse item seja mais bem aprofundado um pouco mais à frente, as perquirições de Nóvoa surgem provocativas e instigantes e, de certa maneira, antecipam algo das nossas próprias perguntas:

A resposta à questão, Porque é que fazemos o que fazemos em sala de aula?, obriga a evocar essa mistura de vontades, de gostos, de experiências, de acasos até, que foram consolidando gestos, rotinas, comportamentos com os quais nos identificamos como professores. Cada um tem o seu modo próprio de organizar as aulas, de se movimentar na sala, de se dirigir aos alunos, de utilizar os meios pedagógicos, um modo que constitui uma espécie de segunda pele profissional (grifos no original) (Nóvoa, 1992, p. 16).

\section{A análise psicológica do trabalho de yves clot}

$\mathrm{O}$ professor e pesquisador francês Yves Clot encontra-se vinculado ao Conservatoire National dês Arts et Méties - CNAM, onde atua na área de Psicologia do trabalho. Seus conceitos teóricos e metodológicos têm sido aproveitados por programas e núcleos de pesquisa das mais diversas áreas, como Linguística, Educação, Sociologia do Trabalho e Psicologia. Embora tenha se originado da Ergonomia, sua proposta atual direciona-se para a chamada análise psicológica do trabalho, buscando compreender as condições teóricas e metodológicas que a constituem.

Importa lembrar também que os trabalhos de Yves Clot integram a chamada escola francesa de Ergonomia, que se diferencia bastante da escola norte- 
americana por direcionar sua atenção para as relações de trabalho, enquanto esta última privilegia as condiçôes de trabalho como objeto de estudo e intervenção. Essa diferenciação é relevante, uma vez que já sinaliza possibilidades de vinculação com matrizes teóricas mais críticas e menos adaptativas.

Em obra recentemente publicada no Brasil, Clot (2006a, p. 11) deixa clara a sua afinidade com a visão marxiana, ao afirmar que "a análise do trabalho visa sempre, de todo modo, a compreender para transformar", bastante próximo da orientação de Marx na Tese XI sobre Feuerbach, a respeito da crítica aos filósofos que interpretam o mundo sem se preocupar com sua transformação. Além disso, há uma clara inspiração nos estudos da Psicologia sócio-histórica de Lev Vygotsky, assumida de forma clara e inequívoca, quando afirma que "trabalho não é uma atividade entre outras. Exerce na vida pessoal uma função psicológica especifica que se deve chegar a definir" (Clot, 2006a, p. 12).

Também baseada em Vygotsky está a proposição de que, para Clot, a atividade psicológica é, ao mesmo tempo, mediatizada (pela linguagem, pelos instrumentos) e mediatizante (produz elo entre objetos, pessoas e sujeito) (Clot, 2006b, p. 25). As derivações dialéticas desse raciocínio servirão para estudar, por exemplo, a questão da ferramenta nas situações de trabalho:

Em situações de trabalho, certas ferramentas não entram nunca na atividade do sujeito. Entram somente se elas podem servir aos objetivos a que esse sujeito se deu, não somente aos objetivos que se lhe deram, mas aos objetivos que ele se deu. Por uma razão evidente, bem simples e forte: é que o artefato/ferramenta não é a origem do instrumento. Ele não é a fonte (la source), a ferramenta é apenas o recurso (la ressource) da atividade. Faço uma diferença muito importante, porque acredito que esta exista no coração da obra de Vygotsky (Clot, 2006b, p. 24) (grifos no original).

É assim que Clot vai defender a ideia de que Vygotsky teria proposto não uma teoria da internalização, mas sim uma teoria da apropriação, pois, no exemplo da ferramenta acima citado, o sujeito impõe sua marca na situação de trabalho, de maneira inevitável e inequívoca. Esse processo de subjetivação do uso do artefato / instrumento de trabalho (ou, como ele mesmo diz, "um desvio visando à subjetividade") é o que constitui a ideia de apropriação.

Para Clot, a dimensão social do trabalho se faz presente na própria realização da atividade de trabalho, executada, que é bem diferente da tarefa prescrita. $\mathrm{Ou}$, como ele mesmo diz:

[A atividade de trabalho] é triplamente dirigida e não de modo metafórico. $\mathrm{Na}$ situação vivida, ela é dirigida não só pelo 
comportamento do sujeito ou dirigida por meio do objeto da tarefa, mas também dirigida aos outros. A atividade de trabalho é dirigida aos outros depois de ter sido destinatária da atividade destes e antes de o ser de novo. Ela é sempre resposta à atividade dos outros, eco de outras atividades. Ocorre numa corrente de atividades de que constitui um elo. No terceiro sentido do termo, o trabalho é, portanto, ainda uma atividade dirigida: atividade dirigida pelo sujeito, para o objeto e para a atividade dos outros, com a mediação do gênero (Clot, 2006a, p. 97).

Há então, primariamente, um componente coletivo na atividade, que deverá ser sempre considerada uma coatividade, pois estará sempre endereçada a um ou vários destinatários. O autor alerta, entretanto, que essa relação não deve ser de oposição ou de anulação, mas de complementaridade. Essa noção de atividade para os outros constituiu objeto de investigação realizada por Yves Clot junto a trabalhadores do serviço de transporte ferroviário (comboios) em Paris. Em seus estudos mais recentes, investigando o trabalho dos professores, Clot irá ampliar a noção de atividade para os outros, buscando analisar as implicações das atividades dos alunos sobre aquelas desenvolvidas pelos professores e seus desdobramentos sobre a relação entre aprendizagem e desenvolvimento (Clot e Yvon, 2004).

Um outro conceito desenvolvido por Yves Clot é o de catacrese, que poderia ser definido como o uso não previsto dos instrumentos de trabalho, caracterizando-se, muitas vezes, como um tipo de enriquecimento de funções desse mesmo instrumento. Não deve ser interpretado como um erro ou desvio, pois, sendo elaborado pelo trabalhador, tem por finalidade mantê-lo vinculado às suas ocupações, apartando-o daquilo que Clot chama de "pré-ocupações". Essas, por sua vez, são formadas por aquelas outras atividades, usualmente de caráter pessoal (problemas familiares, salário, etc.), que ocupam parte do tempo e da atenção do trabalhador.

Em ambos os conceitos, tanto na catacrese quanto nas pré-ocupaçôes, Clot recorre aos escritos de Vygotsky, demonstrando como se efetiva a mudança de um instrumento técnico em um instrumento psicológico, que, em instância final, será um instrumento de gestão do trabalhador sobre si mesmo. Simultaneamente, pode-se observar que, na história das técnicas, é exatamente a implementação de funções novas que transformam os mecanismos ou artefatos (processos prescritos) em instrumentos (alimentados com a criatividade dos sujeitos) (Clot, 2007).

A discussão entre o trabalho prescrito e o trabalho real é retomada por Yves Clot, por meio da diferenciação entre os conceitos de atividade real e o que 
ele chama de real da atividade. A atividade real diz respeito ao que efetivamente é feito, mas seria uma parte relativamente pequena em relação ao que é possível. Esse raciocínio, que se origina dos estudos da Ergonomia e segue para além deles, permite a Clot apresentar a seguinte ideia: há um potencial risco de desgaste do trabalhador no controle da atividade que ele, muitas vezes, não chega a realizar, pois a configuração da atividade a partir do desenho proposto pela tarefa é que se torna cansativa. Como consequência, surge a constatação de que a programação de tarefas a serem realizadas - ou seja, a prescrição - seria tanto melhor (há realmente por Clot uma afirmação valorativa nesse sentido) quanto mais permitisse o sujeito se desenvolver enquanto realiza suas atividades.

É importante lembrar também que essas supostas "transgressões" em relação às tarefas prescritas, para se tornarem instrumentos de trabalho, devem ser compartilhadas e ratificadas no espaço coletivo dos trabalhadores, em determinado lugar e duração, assumindo, assim, uma configuração histórica e, ao mesmo tempo, transitória. Estaria assim se constituindo o que Clot chama de gênero profissional:

Chamamos aqui gênero ao que foi referido anteriormente como um corpo intermediário entre os sujeitos, um intercalar social situado entre eles por um lado e entre eles e o objeto de trabalho, por outro lado. De fato, um gênero une sempre eles, aqueles que participam numa mesma situação, como coautores que conhecem, compreendem e avaliam uma situação da mesma maneira (Clot, 2006a, p. 41).

Clot considera também que o gênero profissional não deve ser visto apenas como pertencimento social, mas também como um recurso para a ação, uma vez que os trabalhadores, muitas vezes, servem-se deles para evitar erros. Esse gênero também poderia ser denominado como trabalho da organização (conjunto de obrigações partilhadas por um grupo em determinado meio profissional) e se articularia, complementarmente, à organização do trabalho (que corresponde à tarefa). Mesmo porque o gênero profissional não está restrito ao sujeito, pois remete sempre ao coletivo, ao grupal e aos registros que são compartilhados por esse grupo ao longo do tempo em situaçóes de atividade, extrapolando em muito a prescrição original (ou tarefa). A função psicológica do trabalho estaria vinculada, portanto, à possibilidade de construção e manutenção de um gênero profissional e sua não efetivação poderia implicar, entre outras consequências, aumento do número de acidentes e sofrimento psicológico.

Clot também incorpora a dimensão individual ao considerar que, muitas vezes, o trabalhador é chamado, ao improviso, a lidar com situações não previstas. Aí surgirá o estilo profissional, vinculado ao gênero: 
O gênero social, definindo as fronteiras movediças do aceitável e inaceitável no trabalho, organizando o encontro do sujeito com os seus limites, solicita o estilo pessoal. [...] O estilo solta ou libera o profissional do gênero, não negando este último, não contra ele, mas graças a ele, usando os seus recursos, das suas variantes, dito de outra forma, pela via do seu desenvolvimento, empurrando-o para a sua renovação. (Clot, 2006a, p. 41; 49).

Note-se que essas ideias mostram-se bem articuladas com o piso vygotskiano, em que o psicólogo francês assenta sua teoria, pois a emergência dos estilos certamente trará desdobramentos sobre os gêneros, criando condições inclusive para a renovação destes últimos. Basicamente, está sendo recuperada aqui a articulação entre significação social e sentido pessoal, cujos fundamentos se encontram em Vygotsky (1993).

Para Clot, seria fundamental a emergência das discordâncias em torno do gênero profissional, uma vez que esse se constitui de muitas variantes. Convidando a Psicologia a estimular o debate e a discussão, o autor entende que é premissa básica ouvir os trabalhadores a respeito de seu próprio trabalho, por meio do que ele chama de autoconfrontação, que seria uma reflexão sobre a atividade de trabalho rotineira. Nesse sentido, seria legítimo dizer que essa proposta de metodologia investigativa de Clot caracteriza-se como uma coanálise do trabalho, uma vez que o objeto focalizado, a atividade, será analisado conjuntamente, quer seja por um analista, quer seja por um dos pares do trabalhador, quer seja pelo próprio trabalhador.

Essa formatação metodológica - segundo o próprio Yves Clot, ainda em construção - teria, pelo menos, dois desdobramentos mais próximos. $\mathrm{O}$ primeiro deles seria a constatação de que a análise do trabalho teria um forte efeito sobre a transformação do trabalho, principalmente no que diz respeito à formação.

A análise do trabalho revela-se um bom instrumento de formação para o sujeito na condição de se tornar um instrumento de transformação da experiência. O que é formador para o sujeito, quer dizer, o que aumenta o seu raio de ação e o seu poder de agir, é conseguir mudar o estatuto do vivido: de objeto de análise, o vivido deve tornar-se meio para viver outras vidas (grifo nosso) (Clot apud Santos, 2006, p. 38).

Exatamente devido ao seu caráter mediador, a proposta de Clot extrapola aquilo que é considerado como a análise tradicional da atividade. Partindo do pressuposto (considerado clássico para a ergonomia e a Psicologia do trabalho francesa) de que a tarefa é o que se tem a fazer (trabalho prescrito) a atividade 
é aquilo que se faz (trabalho real), Clot avança e afirma: "atividade realizada e atividade real também não correspondem uma à outra" (Clot, 2006a, p. 115).

A atividade realizada se aproxima da noção de tarefa (portanto claramente visível e passível de observação direta) e constitui apenas uma ínfima parte do que é possível. Já a atividade real ou real da atividade não está claramente visível e inclui a chamada atividade impossível, não manifesta e, portanto, fora da possibilidade de observação de qualquer analista. É importante dizer, porém: de forma alguma a atividade real está em segundo plano, pois é na realização que se encontram os "novos possíveis". Assim, a análise da atividade deverá considerar "o trabalho psíquico e prático que o trabalhador precisa fazer para transformar o real da atividade em atividade realizada" (Clot, 2007, p. 17).

Buscando fundamentação em Vygotsky ("o homem está a cada minuto pleno de possibilidades não realizadas") e recuperando a ideia de real da atividade, já mencionado anteriormente, Clot organiza seu conceito de clínica da atividade, que buscaria basicamente compreender a dinâmica da ação dos sujeitos (Clot et alii, 2000), sempre lembrando que essa atividade tem três direções: a si próprio, ao objeto de trabalho e aos outros.

Clot também alerta que a clínica da atividade não deve ser confundida com a Psicologia clínica, uma vez que adota tal nomenclatura devido às proximidades que o recurso da análise de trabalho guarda com o método clínico (Clot, 1995). Para ele, o uso do termo clínica não tem a ver somente com a noção de doença ou dos signos/sinais que a definem, mas está ligado à perspectiva de mobilização de ação para modificar as situações vividas pelos sujeitos, onde quer que estes se encontrem (Clot, 2007, p. 15).

No campo da Educação, a análise psicológica do trabalho vem trazendo contribuições importantes. Ao investigar a atividade de um professor de Filosofia, Clot observa o que ele mesmo denomina de uma "metamorfose dos gêneros" profissionais, a partir da construção de um estilo profissional, o qual, por sua vez, "depende da relação do sujeito com sua própria memória operatória e subjetiva” (Clot, 2006, p. 196).

Uma das ideias mais relevantes de Clot para a nossa investigação neste trabalho é a noção de que algumas das atividades desenvolvidas pelo professor observado por ele se efetivavam numa bipertinência genérica, pois o sujeito relatava simultaneamente o pertencimento a dois gêneros: o pedagógico e o sindical.

A atividade relatada e comentada acima pode ser descrita como pertinente a vários gêneros ao mesmo tempo, como uma atividade 
polifônica nesse sentido preciso. Ela circula entre esses gêneros, navega entre eles, encadeia-os. Não obstante, as mudanças de gênero no curso da atividade que assinalam essa bipertinência genérica não ocorrem por si mesmas, como o observa o próprio professor: não relata ele sua fadiga com essas mudanças, com essas transições? Ora, é sem dúvida esse conflito de gêneros que se entrecruzam em sua atividade que lhe fornece uma das bases de seu estilo particular [...]. Isso nos permite avaliar a que ponto o estilo, longe de ser um atributo psicológico invariante, está sempre situado no interior do gênero ou, mais exatamente, no ponto de colisão entre os gêneros que ele combina de maneira diversificada a depender do momento a fim de conseguir libertar-se deles. O estilo é a criação a que o sujeito deve recorrer a fim de dominar o jogo das mudanças de gênero, as passagens entre gêneros (os grifos são nossos) (Clot, 2006, p. 196).

Essa breve apresentação do pensamento de Yves Clot e seus colaboradores permite-nos pensar que as mobilizações subjetivas dos educadores que lidam com a educação profissional poderiam ser mais bem compreendidas se tomássemos como ponto de partida os conceitos por ele defendidos, restaurando a função psicológica na atividade de trabalho desses mesmos educadores.

Ao estudarmos a obra do autor francês, porém, dois pontos principais nos chamaram a atenção. $\mathrm{O}$ primeiro, diz respeito à convergência entre as suas proposições e os postulados críticos de Paulo Freire, com o qual a Psicologia do trabalho de Yves Clot parece aproximar-se claramente, conforme busca a emersão do sujeito crítico, reflexivo sobre as suas próprias práticas, tanto no plano técnico quanto político. O segundo ponto que se destacou para nós a partir do estudo de Yves Clot foi a presença constante e basilar da obra de Vygotsky, desde os principais parâmetros teóricos e epistemológicos até a definição de procedimentos metodológicos, que não desenvolvemos aqui por limitações do texto.

\section{Educadores de ep: novos olhares, possíveis fazeres}

Durante dois anos (2005-2007), nós nos dedicamos à investigação sobre a atividade dos educadores que atuam no campo da educação profissional de nível básico ou inicial. Procedemos à escolha intencional (não aleatória) de práticas de educação profissional que se configurassem como cursos livres, nos termos previstos pela legislação, mais especificamente o Decreto 9.394/1996 (Lei de Diretrizes e Bases da Educação). A escolha foi feita a partir de indicação de setores do poder público, da área acadêmica ou feita pelos próprios sujeitos de pesquisa (educadores de EP). Por se tratar de pesquisa qualitativa, este trabalho renunciou à necessidade de representatividade estatística, comum 
em pesquisas de natureza quantitativa.

Foram entrevistados 15 educadores e 8 gestores, usualmente indicados pelas próprias instituiçôes pesquisadas. Todos foram orientados quanto à finalidade das entrevistas e assinaram termos de consentimento livre e esclarecido, atendendo a recomendações éticas cabíveis. Por limitação de condições de pesquisa, as entrevistas foram usualmente realizadas nas próprias instituições, em salas definidas com antecedência para tal. As entrevistas foram gravadas, transcritas e delas foram extraídos trechos agrupados em categorias, as quais iam sendo construídas e reformuladas progressivamente ao longo da pesquisa, quando necessário.

Foi também adotada a análise de documentos fornecidos pelas instituições ou disponíveis em meio eletrônico (internet). Projetos, relatórios de atividades, balanços financeiros e/ou sociais, quadros demonstrativos e reportagens também foram usados como fonte de informação e estão devidamente citados no final do trabalho. Foram filmadas as atividades de nove educadores, em câmera analógica, com posterior digitalização das imagens em ilha de edição. Cada educador teve filmadas aproximadamente oito horas de seu trabalho, período usualmente dividido em dois dias, de forma a recuperar atividades ou aulas diferenciadas. Todas as autoconfrontaçōes (diretas e cruzadas) foram gravadas, algumas em vídeo, outras apenas em áudio.

A análise dos dados obtidos nos permitiu travar contato com um fato social bastante complexo, de extrema relevância e pouco analisado até então. Tratase da ação crescente e cada vez mais intensa de sujeitos que, individualmente ou em grupos, desenvolvem suas atividades de trabalho por meio de uma função educativa, a partir de percursos por itinerários tão diversos quanto as próprias histórias de vida de cada um.

Diversificados exatamente por não contarem em grande parte com delineamentos mais nítidos por parte do poder público, esses itinerários induzem os trabalhadores que neles se inserem à adoção de modos de ser e fazer que são, visivelmente, as expressóes de si mesmos: discursos, práticas, planos de aula, métodos didáticos ou ferramentas avaliativas carregados de representaçôes sobre como fazer para transformar vidas e ampliar possibilidades/ poderes. Na verdade, são esses itinerários que os conduzem no sentido da construção de gêneros profissionais com configurações mais ou menos inovadores, conforme os contextos organizacionais onde se inserem.

Chamados a formar e a educar sujeitos muitas vezes privados de recursos básicos de socialização, encontramos homens, mulheres, negros, brancos, jovens, adultos, todos identificados principalmente pela técnica 
que dominam em algum nível e que serão chamados a disponibilizar por modelos educativos os quais raramente ajudaram a construir. Em sua maioria, também não obtiveram formação específica no campo pedagógico e guardam a compreensão de que qualquer decisão, no sentido de obter essa qualificação específica, deverá partir deles próprios e não da instituição onde atuam ou do poder público.

Como várias outras categorias profissionais, os educadores de EP de nível básico também experimentam os processos de fragilização dos vínculos e dos contratos de trabalho, com impactos visíveis sobre a remuneração. Se, por um lado, vivem lutas semelhantes às dos demais profissionais da Educação, no que diz respeito à busca de reconhecimento de seu trabalho; por outro, também constatam o mesmo que outros trabalhadores que militam no campo das políticas sociais: "para pobres, projetos pobres". Complementarmente, buscam manter, simultaneamente à função educativa, outras atividades profissionais, seja como educadores em vários programas profissionalizantes, seja como profissionais em suas respectivas áreas de atuação, seja de ambas as maneiras simultaneamente. Em alguns casos, a sobrecarga de trabalho é visível e com alto potencial de adoecimento físico e psíquico.

Esse é um dos desdobramentos surgidos no decorrer do trabalho de forma mais inesperada: a aproximação entre a Psicologia do trabalho e a Pedagogia crítica nos permitiu uma ampliação do espectro de análise ao qual pudemos recorrer para melhor compreender os modos operatórios dos educadores de educação profissional de curta duração, sendo possível destacar os seguintes itens:

a) a consolidação teórica de categorias como subjetividade, atividade, gênero e estilo profissional, catacrese, dentre outros, deixa clara a necessidade de extrapolar discursos dogmáticos que tendem a simplesmente ignorar o desejo e a insistência desses sujeitos em agir na direção da função educativa;

b) para que tal avanço se efetive, de forma consistente e crítica, em um processo de educação realmente libertadora, a metodologia da clínica $d a$ atividade pode constituir uma poderosa ferramenta, pois carrega em suas matrizes grande afinidade com as demandas da Pedagogia crítica;

c) essa metodologia também se configura com enorme potencial para o uso nos processos de formação de educadores, mobilizando gestores, instituições e sociedade a repensar os atuais itinerários formativos e, principalmente, suas lacunas, particularmente no campo da educação 
profissional, cuja ênfase tecnicista ainda parece ser um elemento profundamente arraigado, não somente nas representações dos sujeitoseducadores;

d) as ponderações aqui apresentadas, identificadas na situação particular da educação profissional de curta duração ou inicial, parecem carregar expressivas possibilidades de aplicação em outros níveis, principalmente na educação profissional (técnica e tecnológica) e na educação de jovens e adultos, embora, para tanto, seja recomendável o aprofundamento das especificidades dessas modalidades de ensino;

e) as instituiçõos onde se efetivam grande parte dos programas e cursos de educação profissional de nível básico, particularmente no setor privado, ainda não se mostram tão dispostas ao investimento na adoção de metodologias de formação de seus educadores, particularmente nas que não enfatizem conteúdos técnicos ou que não se limitem à transmissão/revisão de modelos pedagógicos tradicionais, essencialmente funcionalistas;

f) conforme tais instituições constituem na verdade extratos da sociedade onde se inserem, permite-se pensar que cabe aos atores sociais mais preocupados com o incremento de práticas pedagógicas mais libertárias a defesa das análises críticas e sensíveis aos depoimentos dos trabalhadores, que seriam, a nosso ver, o recurso fundamental para conhecer a concretude dos processos de educação profissional de curta duração;

g) pela premência que o campo da educação profissional de curta duração tem, particularmente para as camadas populares, é fundamental que as políticas públicas relacionadas tenham proximidade com essa dimensão real e concreta do trabalho de seus educadores, atentando para a transversalidade das suas atividades, uma vez que setores público e privado, muitas vezes, compartilham do trabalho desses mesmos sujeitos.

Certamente, essas reflexões ultrapassam o caminho das perquirições que fazíamos ao iniciar este trabalho. Acreditamos ser esta mesma uma característica bem própria do processo de investigação científica, que impóe ao pesquisador a realidade de sua própria ignorância, por mais que se descubra. Recorrendo a essa ideia, o que poderíamos dizer que "descobrimos" nesta tese? Exatamente que a atividade dos educadores que atuam no campo da educação profissional de curta duração, ainda é na atualidade, uma atividade marginal, no sentido de que se desenvolve perifericamente em relação a outras atividades profissionais desses mesmos educadores; entretanto, apesar disso, conforme sobrevivem por tempos 
e espaços sociais distintos, permite pensar que é significativo o impacto que produzem sobre as instituições e sobre as comunidades onde atuam, sinalizando possibilidades de transformação efetivas da realidade social que experimentam.

Se a Educação (de forma geral) e a educação profissional (em particular) têm sido historicamente usadas pelas classes dominantes para sustentar práticas compensatórias destinadas a manter um status quo de subserviência e resignação por contingentes expressivos da população brasileira, a análise da atividade dos educadores de EP de nível básico revela um potencial de enfrentamento dessa construção histórica, potencial esse ainda a ser explorado.

São esses sujeitos, que optam por inserir-se no métier educativo, que carregam as reais possibilidades de implementação de políticas públicas integradas de geração de renda, profissionalização, educação e trabalho. A técnica que dominam deve ser objeto de reflexão e crítica pelos agentes públicos e pelas organizações, sem dúvida. Mas, principalmente, por eles mesmos, levando-os a questionarem a quem e quais interesses se beneficiam do trabalho que desenvolvem. Estado e ONGs devem oferecer itinerários formativos que permitam com que tais educadores, assim os enxergamos, ampliem sua capacidade de intervenção ao incorporar uma visão crítica dos processos de qualificação da força de trabalho.

Essa coreografia entre ensinar e aprender, tão defendida por Paulo Freire e outros, parece-nos ser uma condição básica a ser assumida por programas de educação profissional de nível básico, tanto os mantidos pelo poder público quanto pela sociedade civil. Somente essa compreensão dialética pode corrigir o idealismo ingênuo - e, até certo ponto, perverso sustentado por agentes dos mais diversos matizes políticos e ideológicos, de que o saber técnico significa, por si mesmo, o poder absoluto que garantirá uma inclusão permanente e definitiva. Há que se considerar quem se integra onde e para que fim, a que preço e em detrimento de quantos, sem o que qualquer movimento, por mais digno que possa parecer a quem o sustenta, redundará na manutenção da miséria material e moral que já observamos e que de que tanto nos ressentimos.

\section{Referências}

Aranha, A. V. S. (2000). A formação profissional na Fiat Automóveis e a padronização internacional de trabalhadores da empresa. Tese de Doutorado em História e Filosofia da Educação, Pontifícia Universidade Católica de São Paulo, São Paulo. 
Aranha, A. V.S. (s.n.). Formação docentepara a educação profissional: especificidades para a área da saúde. Trabalho não publicado.

Arroyo, M. (2006). Formar educadores e educadores de jovens e adultos. In: Leôncio Soares. Formação de educadores de jovens e adultos. (pp. 17-32). Belo Horizonte: Autêntica.

Berger Filho, R. L. (2002). Formação de formadores para a educação profissional: um processo de aprendizagem sustentável da cidadania. Formação, 2(4), 73-80.

Bicudo, M. A. V. \& Junior, C. A. (org.). (1996). Formação do educador: dever do Estado, tarefa da Universidade. São Paulo: EDUSP.

Burnier, S. (2007a). Histórias de vida de professores: o caso da educação profissional. Revista Brasileira de Educação, 12 (35), 343-358.

Burnier, S. (2007b). A docência na educação profissional. In: Anais da 29a Reunião Anual da ANPED. Caxambu: ANPED. Recuperado em 26 de março, 2008, de www.anped.org.br/reunioes/29ra/trabalhos/trabalho/GT08-1838-Int.pdf

Charlot, B. (2000). Da relação com o saber. Porto Alegre: Artes Médicas Sul.

Charlot, B. (2005). Relação com o saber, formação dos professores e globalização: questões para a educação hoje. Porto Alegre: Artes Médicas.

Clot, Y. \& Faita, D. (2000). Genres et styles em analyse du travail. Travailler, 4, 7-42.

Clot, Y. \& Yvon, F. (2004). Apprentissage et développement dans l'analyse du travail enseignant. Psicologia da Educação, (19), 11-38.

Clot, Y., Faita, D., Fernandez, G. e Scheller, L. (2000). Entretiens en autoconfrontation croisée: une méthode en clinique de l'activité. Pistes - Réflexion sur la pratique. (2) 1. Recuperado em 27 de dezembro, 2006, de http://pettnt/ v2n1/articles/v2n1a3.htm.

Clot, Y. (2006a). A função psicológica do trabalho. Petrópolis: Vozes.

Clot, Y. (2006b). Vygotksi: para além da Psicologia cognitiva. Pro-posiçōes, 17 (2), 19-29.

Clot, Y. (2005). Entrevista. Psicologia da Educação, (20), 155-160. 
Clot, Y. (1989). O marxismo em questão: posfácio. In: P. Silveira \& B. Doray. Elementos para uma teoria marxista da subjetividade. (pp. 179-191). São Paulo: Vértice.

Di Pierro, M. C. (2006). Contribuições do I Seminário Nacional de Formação de educadores de Jovens e Adultos. In: L. Soares (org.). Formação de educadores de jovens e adultos. (pp. 281-292). Belo Horizonte: Autêntica.

Nosella, P. (2004). A formação do educador e do professor: esboço históricofilosófico. In: Anais do II Congresso Internacional de Educação. (pp. 01-31). Santa Fé (Argentina): Universidad Nacional del Litoral, Facultad de Humanidades y Ciências.

Nóvoa, A. (org.). (1992). Vidas de professores. Coleção Ciências da Educação. Porto (Portugal): Porto Editora.

Oliveira, M. R. (2005). Formação e profissionalização dos professores do ensino técnico. In: A. V. S. Aranha, D. M. Cunha \& J. B. Laudares. (org). Diálogos sobre trabalho: perspectiva multidisciplinar. (pp. 03-09). Campinas: Papirus.

Perrenoud, P. (2002). As competências para ensinar no século XXI: a formação dos professores e os desafios da avaliação. Porto Alegre: Artmed.

Ribeiro, V. M. (1999). A formação de educadores e a constituição da educação de jovens e adultos como campo pedagógico. Educação e Sociedade, 20(68), 184-201.

Santos, M. (2006). Análise psicológica do trabalho. Laboreal. 2 (1), 34-41.

Tardif, M. (2002). Saberes docentes e formação profissional. Petrópolis: Vozes, 2002.

Vygotsky, L. S. (1984). Formação social da mente. São Paulo: Martins Fontes.

Vygotsky, L. S. (1993). Pensamento e linguagem. São Paulo: Martins Fontes. 